\title{
Relaunching National Evaluation and Quality Assurance: Expectations and Preparations
}

\author{
Christina Segerholm
}

\begin{abstract}
In this chapter, we describe and analyse the design of the evaluation and quality assurance system decided by the Swedish Parliament in 2016. Particular stress is put on how one part of this system - the institutional reviews of the higher education institutions' internal quality assurance processes - was set up by the Swedish Higher Education Authority (SHEA). The aim was to explore governing of higher education in the signals expressed through the design and requirements decided by the SHEA. The SHEA public reports, guidelines, criteria, and templates for the higher education institutions and evaluators, and interviews with SHEA staff were used for this purpose. The analysis shows that the Standards and Guidelines for Quality Assurance in the European Higher Education Area were important influences in the design work. It also shows that the design supports the governing by objectives and outcomes logic and a notion of "quality" in higher education as equivalent to work with internal quality assurance systems at higher education institutions. We argue that this design forms the basis for constitutive effects like an instrumental notion of higher education.
\end{abstract}

\section{Introduction}

Throughout the book, we have described and analysed the emergence of evaluation and quality assurance in the Swedish higher education system, with particular emphasis on the most recent developments. Here we will concentrate on the 2016 system, which was preceded by the highly criticised 2011-2014 system, and later by a period without national evaluation and quality assurance (EQA) characterised by a multitude of activities and discussions throughout higher education. Commissioned to develop a new national system, the Swedish Higher Education Authority (SHEA) worked intensely to create a design for a new EQA system, first

\footnotetext{
C. Segerholm $(\bowtie)$

Department of Education, Umeå University, Umeå, Sweden

e-mail: christina.segerholm@umu.se
} 
from autumn 2013 to spring 2014, at which time the government decided to appoint a special investigator. Later, when the parliament decided on the new system from spring 2016, the SHEA intensified its design work. During this period of reform interval, higher education institutions were occupied with creating and improving internal quality assurance systems that should match requirements not yet decided, as described in the chapter "Enacting a National Reform Interval in Times of Uncertainty: Evaluation Gluttony Among the Willing".

To reiterate, in March 2016, a new national EQA system for higher education was decided by the parliament. Signals to the higher education institutions (HEI) of what parliamentary decision to expect had been disseminated by a government memorandum outlining the planned system. The SHEA had also worked to spread information and collect comments about what was thought would be decided by the parliament, particularly during autumn 2015, as the chapters "Hayek and the Red Tape: The Politics of Evaluation and Quality Assurance Reform - From Shortcut Governing to Policy Rerouting" and "Enacting a National Reform Interval in Times of Uncertainty: Evaluation Gluttony Among the Willing" show. The ramifications of the new system were finally decided in March 2016. The government then commissioned the SHEA to work out the design and details and how to best implement the system. What then, did this system, look like?

In this chapter, we describe this 2016 national EQA system and pay particular attention to one component, institutional reviews of higher education institutions' internal quality assurance (IQA) systems. Our aim is to analyse this national system as a matter of what it is meant to achieve (not what it actually achieves or how and what it influences), the motives, and the direction of the governing process (what is evaluated and how) as it appears in SHEA documentary materials and staffs' experiences. We argue that the designs of national EQA systems direct attention to different parts of the HEIs' activities and organisations, and as such, designs are also part of governing higher education.

We used the following questions to organise our work with the chapter:

- What is evaluated in the 2016 national evaluation and quality assurance system? Why? By whom? How? With what consequences in terms of expectations?

- How is the work of designing the 2016 national evaluation and quality assurance system described by the SHEA actors?

- What knowledge and ideas are valued and promoted within the 2016 system in general and in the institutional reviews in particular?

- What are the implications for higher education governing?

In the chapter "Governing by Evaluation: Setting the Scene", we underscored an understanding of governing as a variety of deliberate processes and work performed by different actors, in different places through policies and various means and activities (Clarke 2015). Apart from describing the actual design of the 2016 national EQA system, this understanding also directs us to pay attention to the actors at the SHEA and their experiences in the design work. As this chapter in a way is a continuation of the retrospect in the chapter "National Evaluation Systems", we once again make use of a view of higher education based on Hopman's (2003, 2008) 
idea of a move in management, from being an internally "ill-defined problem" controlled and evaluated by professionals (colleagues/peers) called "management by placement" to a "well-defined problem" managed, controlled, and evaluated by external "expertise" using indicators and standards, called "management by expectations". Following Hopman's argument, this move is connected to issues of accountability in institutionalised practices like education, where the boundaries are weak and changing over time, rendering them "ill-defined". As education expands and its problems become even more "ill-defined", accountability demands may be harnessed by a transfer to a more "well-defined" enterprise through the use of indicators, standards, and EQA systems, since "accountability needs something that can be counted, or where it is at least possible to measure the distance between expectations and results" (Hopman 2008, p. 425). Consequently, expectations in our text denote what is at the fore of the design of the national EQA system, in the expectations, ideas, and values it promotes.

This understanding can be combined with what Dahler-Larsen $(2012,2014)$ analyses as "constitutive effects". Constitutive effects are constitutive in the sense that evaluative activities like EQAs - including indicators, criteria, and guidelines affect the phenomena, enterprises, or practises that are assured, assessed, or evaluated. Or, as Dahler-Larsen phrases it in relation to performance indicators: "The indicator helps define the concept it claims to measure" (Dahler-Larsen 2014, p. 975). This means that the designs of the national EQAs are in part defining what quality is in higher education, as well as signalling ideas of what higher education and HEIs are all about.

The chapter rests on documentary materials like public reports from the SHEA, guidelines and templates for the institutional reviews as they were tested in a pilot and quite extensive interviews with nine SHEA staff in different positions during 2015 and 2016 when the new national system was developed and implemented.

\section{The 2016 EQA System: Suspenders and Belt}

The government's arguments for the new national evaluation and quality assurance system stressed the importance of high quality in higher education in order for Sweden to be competitive and secure future work opportunities (Ministry of Education 2015, p. 3). Large investments in higher education that have proven profitable are to be followed by continued expansion of the higher education system. This calls for persistent efforts to increase quality, it was said (ibid.) One objective was that: "(a)ll female and male students should know that they receive education of high quality" (ibid.). National quality assurance was put forward as the means to achieve this. These hopes were later formulated into objectives by the SHEA, stating that the planned system was both to control the performance of study programmes and to work for quality improvements (SHEA 2016a, p. 6, b, p. 6). This balance between a system that both controls and develops is hard to strike, as was testified by staff at the SHEA: 
This is a role that we have, that these evaluations shall lead to development and the system shall be supportive, and at the same time we shall control because it is after all public funds that are used, and this ought to be controlled so they are used in the right way. It is a challenge. (SHEA staff 4, September 2016)

One prominent idea with this EQA system is that the HEIs should take on a more active role in quality assurance through internal quality assurance systems (IQA), while the SHEA should be responsible for evaluating these internal systems. "They [the HEIs, our clarification] have the major responsibility for, or they have the responsibility for quality in higher education..." (SHEA staff PB6, November 2015). Another idea of note is that the national system is to be cohesive so that it "is useful for all four components" (SHEA 2016b, p. 7; see below about components) of the system and also supports the HEIs' internal quality assurance systems. An additional pronounced idea, and also an aim, is that the system should "not only have international legitimacy, but also ultimately contribute to a greater internationalisation of Swedish higher education" (SHEA 2016b, p. 5). This is done by adhering to the Standards and Guidelines for Quality Assurance in the European Higher Education Area (2015) or the ESG. When the entire system is in place and running, the SHEA once again plans to apply for membership in the European Association for Quality Assurance in Higher Education (ENQA) (SHEA 2016a, p. 12; SHEA 2016b, p. 12). ${ }^{1}$ This is thought to enhance legitimacy for Swedish higher education abroad and facilitate student and faculty mobility. Throughout the SHEA's development work with the national system, the ESG and ENQA membership was at the fore:

...in order for us to live up to our ENQA membership, we have to do reviews of the HEIs' internal quality assurance systems, and this is something that the sector itself and the politicians stress. (SHEA staff 1, September 2016)

In the chapter "Europe in Sweden", we concluded that the SHEA has been, and still is, a central brokering/dissemination organisation for European policy on higher education and quality assurance. This is even more evident in their development work and design of the latest EQA system. The importance of the European perspective and ENQA membership is present in the SHEA report to the government, where there are constant referrals to the ESG.

Looking at other national EQA systems (the Nordic countries, England, Scotland, and the Netherlands) and relying on the internal knowledge and experience in the SHEA were important in developing of the system:

And it is a strength that we have so much experience to get both from other countries, but also from our own experience. We, in fact, have now very much experience in the organisation of evaluations, at different levels. We have the old ones, we looked at previous systems, and we have looked at processes before. We have looked at outcomes before. Now we pick the best parts of our history. (SHEA staff 4, September 2016)

\footnotetext{
${ }^{1}$ In February 2019, the SHEA announced that the process of applying for ENQA membership had begun (SHEA 2019).
} 
Compared to the preceding national EQA system, the increase of what the HEIs must pay attention to is striking. As we presented in the chapter "Enacting a National Reform Interval in Times of Uncertainty: Evaluation Gluttony Among the Willing", the EQA system is comprised of four components or types of evaluations:

- Appraisal of applications for degree-awarding powers

- Institutional reviews of the higher education institutions' quality assurance processes

- Programme evaluations

- Thematic evaluations. (SHEA 2016b, p. 16)

The first component assesses whether or not sufficient conditions exist in order for a HEI to award degrees and licenses. The second directs attention to how the HEIs' internal quality assurance activities and organisation manage to "ensure" that all courses and programmes are good enough. The third type is the evaluation of quality in study programmes and focuses on outcomes and student attainment as they are laid down in the Higher Education Act, the Higher Education Ordinance, and System of Qualifications - that is - the expected learning outcomes for different degrees and licenses (SFS 1993:100, appendix 2). The fourth component, thematic evaluations, may include such areas as sustainable development and the HEIs' work therein.

The four SHEA evaluation types also entail reviewing and assessing four so called aspect areas. They are (a) "governance and organisation"; (b) "environment, resources, and area"; (c) "design, teaching/learning, and outcomes"; and (d) "follow-up, actions, and feedback" (SHEA 2016b, p. 17). The last aspect area is integrated into the other three aspect areas, and so its assessment criteria for that aspect area are included in those of the aspects. On top of that, the evaluations include three perspectives: student and doctoral student, working life, and gender equality (see Fig. 1). The SHEA claims that all these components, aspect areas, and perspectives are based on Swedish law and ordinances and the ESG (SHEA 2016b, pp. 17-19). The gender equality perspective is a special assignment from the government and is something that "is close to their heart" (SHEA staff 3, September 2016).

All evaluations in the national EQA system are carried out through the HEIs' so called self-evaluations, external assessment panels with on-site visits and public reports with decisions and follow-ups. Different aspect areas are emphasised for each component evaluated (see Fig. 2). For example, all aspect areas are included in institutional reviews while in programme evaluations focus on aspect areas, "environment and resources" and "design, teaching/learning, and outcomes" (SHEA 2016a, p. 21). Also included in the programme evaluations - and part of the basis for judgements - are students' pre-graded degree projects (independent work papers). These are to be assessed by the external panels in order to judge whether or not the expected learning outcomes have been attained for different licenses and degrees (SHEA 2018a, p. 15).

As can be seen, the EQA system encompasses several different types of evaluations that target different parts of the HEIs. This comprehensiveness of the system is something the informants at the SHEA also brought up as a possible problem: 


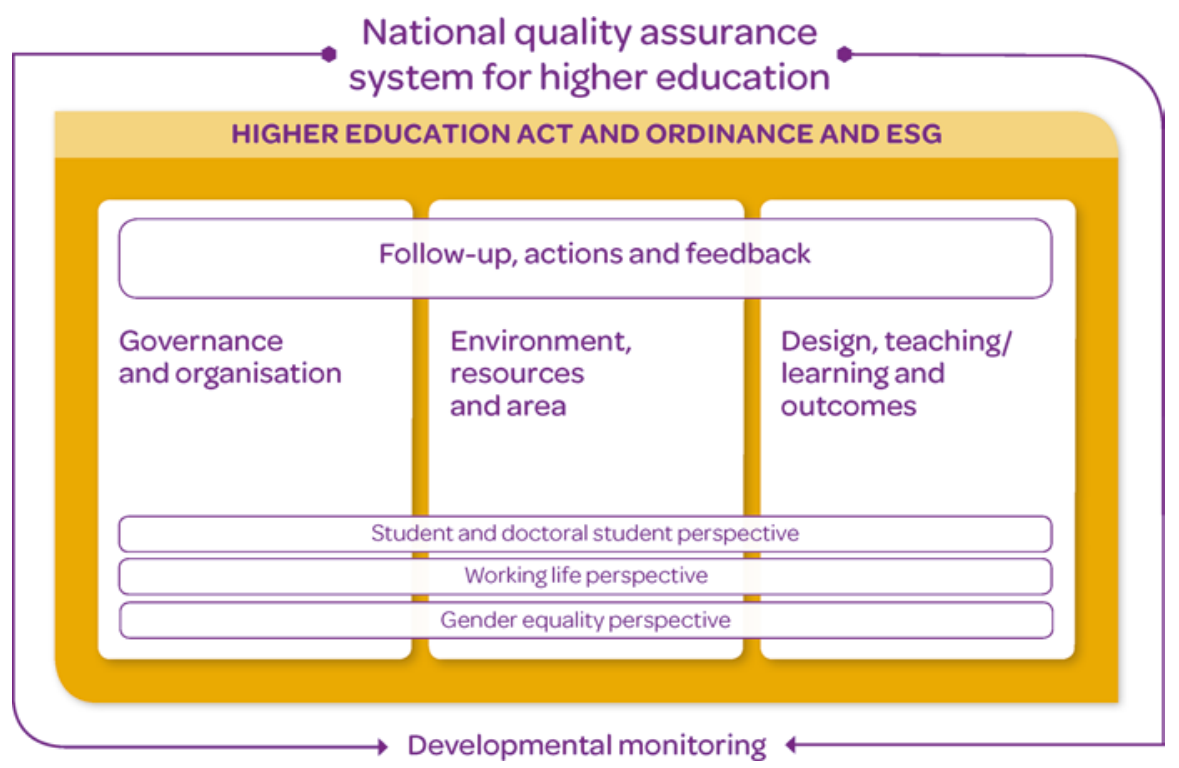

Fig. 1 Overview of components, aspect areas, and perspectives in the 2016 EQA system. (SHEA 2016b, p. 18)

National quality assurance system for higher education

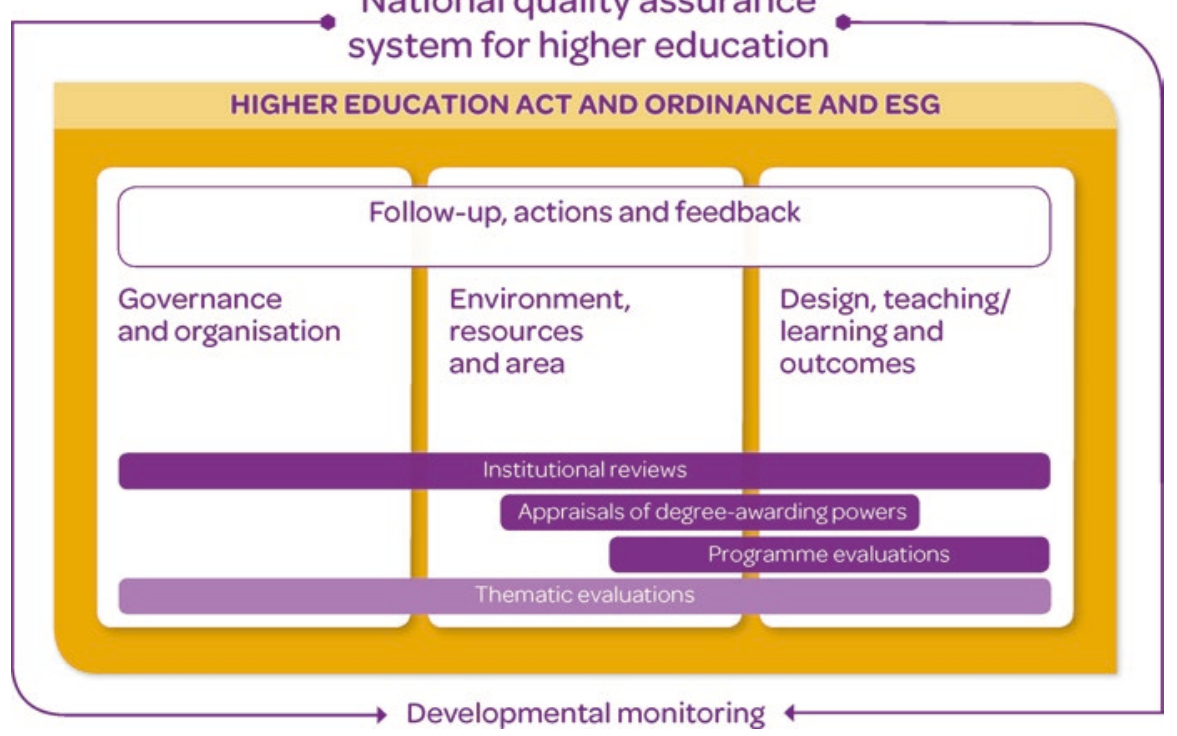

Fig. 2 Overview of what aspect areas and perspectives that are emphasised in the different evaluation types (components). (SHEA 2016b, p. 21) 
... I have said several times that I think this [the national system, our clarification] maybe will be too resource demanding. We get a bit too little out of it in relation to all the resources we put into it. Perhaps we should have skipped some of these parts. (SHEA staff 2, September 2016)

A general weakness in the whole system might be that we are now starting a giant system that includes, that is, I don't think we've had this comprehensiveness in any other national system. (--) Can we and the higher education institutions cope with this? (SHEA staff 3, September 2016)

As part of the design work and implementation process, several activities were carried out in which the evolving design was presented and feedback was collected in meetings with five reference groups that commented on the system as a whole and on the specific types of evaluations, i.e. the different perspectives, or evaluations directed at specific levels or education programmes, like teacher education (SHEA 2016 b, p. 49). More active work was also asked from the advisory group concerning the whole system and meetings with three advisory groups for specific levels or education programmes (ibid.). Furthermore, SHEA staff travelled around the country and arranged several meetings at different HEIs, in which the national system was presented and discussions were held with representatives from the HEIs. This also gave the HEIs opportunities to compare their work with the development of their internal quality assurance systems (Observation notes 12 May 2016, SHEA presentation at Faculty of Social Sciences, Umeå University). Information about the design process, information meetings, etc. was continuously displayed at the SHEA website and in their monthly newsletters.

All four types of evaluations (components) were tested in small-scale pilots during 2016-2017. These pilots were also a planned effort to implement the 2016 EQA system; we portray the pilot of institutional reviews in the next chapter. Several meetings with HEIs and external assessment panels involved in this particular pilot were carried out, and in all these evaluation processes, SHEA staff had an important role: they acted as project and process leaders, steering the evaluation processes forward and arranging all kinds of practicalities, like schedules for interviews, site visits with HEIs, and meetings and coordination of different assessors' written statements. According to the SHEA staff, it was crucial in their work to know about the Swedish higher education system, to have an academic degree in any subject, and to be socially competent and able to lead an external panel in their assessment work. They have opportunities to continuously develop their knowledge in evaluation - particularly about quality assurance - by attending international conferences, most often in the Nordic and European countries.

In October 2016, the SHEA estimated the following numbers of the different types of evaluations during 2016-2022: approximately 20 appraisals of applications for degree-awarding powers, 46 institutional reviews, 650 programme evaluations, and 2-3 thematic evaluations (SHEA n.d.). 


\section{Comments on the Design Work of the EQA System}

Designing evaluations for different purposes like control/accountability or development and capacity building is not easily done, since different purposes direct attention to different parts of what is evaluated. The Swedish EQA system is meant to entail both control/accountability/compliance and support/development/improvement of quality, meaning it has to collect information of all sorts of preconditions, processes, and outcomes at several levels in the HEIs (see, e.g. Owen 2006 for different types of evaluations for different purposes). Assessment criteria also have to be developed for each of these parts. The SHEA staff expressed some critical insights about the system's comprehensiveness, both concerning their own work and on behalf of the HEIs. It is rather easy to imagine the enormous amount of time that has to be spent on collecting information, making sense of it in self-evaluations, assessment processes, writing reports, etc. Any given HEI is probably going to be involved in and have to respond to a number of these nationally required EQA processes, as well as carry out their internal system processes. Over the years, and through working with the requirements of different national EQA systems, the staff are likely to accumulate knowledge on EQA and the different meanings of quality in higher education.

Designing the 2016 national EQA system, implementing it, and thus making it the national policy entail a lot of work: internal activities at the SHEA discussing different approaches and directions of the system, arranging meetings with reference and advisory groups and HEIs, visiting and learning about other countries' national systems, continually up-dating and disseminating information, etc.

What we now see is a national system that has parts of all the previous systems that were described in the chapter "National Evaluation Systems" or covers most ingredients of evaluations in higher education (Harvey 2010). It may be conceived as a sort of sedimentation/layering (Bleiklie and Kogan 2007, p. 482) of former ideas, expectations, experiences, activities, and knowledge. However, as Harvey and Newton point out, it is not easy to know exactly what the purpose(s) of the national system is, whether it is "the educational provider, or the specific programme, or the learner, or the output of the programme or the institution" that are the ultimate aim (Harvey and Newton 2004, p. 150); rather, it is all the evaluation objects that are targeted by the four components. Following Harvey and Newton (2004) and their analysis of external quality evaluations in higher education, it can be argued that the model of self-evaluation, external review, public report, and follow-up may not be the most appropriate for all these different purposes, intentions, directions, aspect areas, and perspectives. When the SHEA fully and energetically emphasises and incorporates the ESG, this also means that the EQA system indirectly promotes a behaviouristic view of learning, as the ESG concerned with learning, teaching, and assessment (Standards and Guidelines for Quality Assurance in the European Higher Education Area 2015, p. 12) is based on and sustains a behaviourist epistemology with predefined end behaviour and outcomes, as shown by Murtonen et al. (2017). Apparently, this is also something that goes hand-in-hand with the 
implementation of the Bologna Process (Murtonen et al. 2017, pp. 114-117). Several research studies have shown that such an epistemology is a restricted theoretical basis for education, teaching, and learning because these processes also include cognitive and social processes that are more open-ended as to what the knowledge outcomes may be (Murtonen et al. 2017). As a complimentary understanding of learning, Marton et al. (2008) offer a viewpoint based on phenomenography in order to achieve higher order learning, holistic understanding, and deep learning in higher education.

With these remarks about the overall 2016 EQA system, we move to the component institutional reviews of the HEIs' internal quality assurance systems. The reason we concentrate on this evaluation type is that it is the most comprehensive one; this type was also underscored in policy texts, arguing that more responsibility for quality in higher education should rest on the higher education institutions themselves.

\section{The Institutional Reviews: Quality as Assuring Quality Assurance}

In this section, we describe the design of the institutional reviews of HEIs' internal quality assurance systems as it was set up for the pilot of this type of evaluations. Pilots were performed as part of the implementation process of the new national system.

In the Swedish language guidelines, the purpose of the institutional reviews is stated as:

to control that the HEIs' internal quality assurance work ensures high quality in courses and programmes, and to contribute to the HEIs' quality development. (SHEA 2016c, p. 8, our italics)

Time and resources were also spent on translating these guidelines into English in order to facilitate international understanding or make recruitment of foreign assessors easier, as we understand it. The meaning is slightly different in the English translation and is an example of how the meaning is somewhat changed in the processes of translation. In our view, the Swedish version expresses a harsher tone, compared to the English version, reading as follows:

to examine whether these processes ensure high quality courses and programmes and to support the HEI's quality improvement efforts. (SHEA 2016d, p. 8, our italics)

There is also another purpose, linked to European policy. Again, it has to do with Sweden's - or to be more precise, the SHEA's - membership status in the ENQA. In order to be eligible according to ENQA requirements, the applicant has to live up to all ESG. The HEIs' internal quality systems are a cornerstone of these requirements that must be reviewed by an external evaluation agency, as described in the chapter "Europe in Sweden". With reference to these ENQA requirements, one SHEA staff said: "We can't say that Sweden should have its own sort, (---) So therefore, the new 
ESG have been very central. We have worked a lot with them when it comes to this component, the institutional reviews" (SHEA staff 2, September 2016).

Other ambitions with the institutional reviews are to push the HEIs "a step further" and to have them ask questions like:

...but how do you know that you have control? What do you have, how can you verify it and how do you use the information you get? What measures do you take if you find things that work a bit poor, and at the same time how can you spread good examples? (SHEA staff 1 , September 2016)

The institutional reviews are said to be based on the Higher Education Act, the Higher Education Ordinance, the System for Qualifications, and the ESG. The importance of the ESG was repeatedly stressed by the SHEA staff:

We worked a lot in relation to the ESG when it comes to the institutional reviews. So, the ESG have become a very, (---) that is, the ESG have been revised during this period, so there were new ESG. [We] translated them into Swedish. It is the ESG in English that are valid, but we did a Swedish translation and put down quite a lot of resources into it. (SHEA staff 2, September 2016)

These institutional reviews are aimed at assessing how well the HEIs' internal quality systems contribute to "ensure and improve the quality of courses and programmes at all education cycles, and covers all aspect areas and perspectives" (SHEA 2016d, p. 9). Furthermore, the reviewers assess how systematic, effective, and proactive the HEIs' internal quality systems are, as well as their integration in the HEIs' organisation and the activities they have. It is clear from the guidelines for the institutional reviews that such characteristics are necessary in order to be judged adequate.

The aspect areas and perspectives in the institutional reviews are the same as the ones listed above, and every aspect area is in turn divided into a number of narrower aspects. These different aspects and the three perspectives are each assessed based on criteria developed for that particular aspect or perspective (SHEA 2016c, p. 9). Criteria for the different aspects closely follow the ESG; even so, some modifications are visible due to the national context and how to translate and interpret the ESG so as to fit Swedish legislation and academic tradition.

There are different types of materials that are part of the reviews and on which the judgements are made, including descriptive statistics from the SHEA, a so-called self-evaluation report by the HEIs, a student report, web interviews, site visits, and areas of focus (SHEA 2016d, pp. 9-12). The self-evaluation report should be no longer than 50 pages, written in a set template developed by the SHEA and organised around the main ESG (Part 1) within each aspect area (see Fig. 3).

As an example, Part 1 of the ESG is directed at "Student-centred learning, teaching and assessment" (Standards and Guidelines for Quality Assurance in the European Higher Education Area (ESG) 2015, p. 12). One of the guidelines for that standard reads: "The assessment allows students to demonstrate the extent to which the intended learning outcomes have been achieved" (ibid.). In the guidelines for the pilot of the institutional reviews, this is operationalised into the assessment criteria: 
cont. Aspect area: Design, teaching/learning and outcomes

\subsection{Aspect: Goal attainment}

\begin{tabular}{ll}
$\begin{array}{l}\text { Assessment } \\
\text { criteria }\end{array}$ & $\begin{array}{l}\text { A. The HEl ensures that its courses and programmes are } \\
\text { designed, developed and implemented with a clear connection } \\
\text { between national and local goals, teaching activities and } \\
\text { examinations. The HEl ensures that all students have good } \\
\text { potential for achieving their established goals within the planned } \\
\text { time. }\end{array}$ \\
& $\begin{array}{l}\text { B. The HEI works systematically to follow up and evaluate whether } \\
\text { students' actual learning outcomes correspond with the expected } \\
\text { learning outcomes. Planned or implemented measures following } \\
\text { such a review are communicated to the relevant stakeholders. }\end{array}$ \\
\hline $\begin{array}{l}\text { Guidelines for } \\
\text { HEls }\end{array}$ & $\begin{array}{l}\text { for meeting the assessment criteria and analyse the strengths } \\
\text { and areas for improvement. It is good to illustrate the report } \\
\text { with specific examples of how the systematic quality assurance } \\
\text { procedures are evident in and contribute to improving the } \\
\text { operation. In addition, include the student and doctoral student } \\
\text { perspective, employer and labour market perspective and gender } \\
\text { equality perspective when relevant. }\end{array}$
\end{tabular}

Fig. 3 Illustration of try-out guidelines translated into English by the SHEA. (SHEA 2016d, p. 25)

The HEI works systematically to follow up and evaluate whether students' actual learning outcomes correspond with the expected learning outcomes. Planned or implemented measures following such a review are communicated to the relevant stakeholders. (SHEA 2016d, p. 25) ${ }^{2}$

The HEIs should assess how well their internal quality assurance system fulfils the requirements set in the guidelines for all aspects and perspectives (SHEA 2016d, p. 25). The student report is meant to give students a chance to express their views on five pages at a maximum. The SHEA materials, the self-evaluations, and the student reports should be uploaded to a particular electronic system that the SHEA has developed for this purpose, called UKÄ Direkt (ibid.).

In the description of the pilot of institutional reviews, web-based interviews are to be conducted approximately 5 weeks after the self-evaluations have been uploaded in UKÄ Direkt. One purpose of these web interviews is to clarify issues raised from the self-evaluations and to prepare areas of focus (SHEA 2016d, pp. 11-12) chosen by the external panel in order to check whether or not claims in the self-evaluation reports are really practised. For example, the panel could check if course evaluations are systematically performed and their results communicated to relevant stakeholders. Areas of focus are checked in the site visit, mainly by

\footnotetext{
${ }^{2}$ This wording is not dramatically changed in the revised guidelines from 2018 (SHEA 2018b, p. 14).
} 
interviews with head management, academic leaders, faculty, and students and/or doctoral students (ibid.).

The number of assessors in the external assessment panel for the institutional reviews is not specified, in the pilot guidelines (SHEA 2016d, pp. 12-13). However, other requirements on the external panel include at least one assessor with international experience and one assessor with expertise in the Swedish higher education system. One assessor should be a student representative, and another must be an employer and labour market representative (ibid.). Furthermore, the instructions in the guidelines list what the assessors' assignments as:

- Discussing the assessment of aspect areas, aspects, perspectives, and assessment criteria

- Participating in meetings during the entire evaluation process

- Representation at the initial meeting with the HEIs to be included in the evaluation

- Reviewing the various assessment criteria, justifying the reviews in writing, and specifying what data the reviews are based on

- Jointly preparing questions for interviews with HEI, student, and any employer and labour market representatives that the HEI cooperates with

- Summarising the assessments in a joint statement including the assessment panel's joint judgement and proposed decision (SHEA 2016d, p. 13)

The HEIs are asked to nominate assessors to the external assessment panels, but the SHEA has the final say. It is sometimes hard to compose a panel from the nominations, meaning that the SHEA staff have to recruit assessors:

but it was, it was just two out of four who I picked from the nomination list (---) one assessor who was in the old, that is, when we reviewed the HEIs' internal quality systems in an earlier cycle 2008 or 2009. (Hawke project leader SHEA, ${ }^{3}$ March 2017)

Once recruited, the assessors should partake in a short training session (1-2 days in the pilot) to inform them of this particular type of evaluation, the ESG, and, most importantly, to ensure they have a common understanding of the criteria and that the review is carried out as it is supposed to be carried out: "( $\mathrm{t}$ )heir assignment and role should be clear, and they should understand, have a common picture of the whole" (SHEA staff Utb, March 2017). They are also informed about the electronic device on which they communicate within the panel, the UKÄ Bedömarvy. According to the SHEA staff, useful knowledge, competences, and/or experiences for the external assessors are that they "have worked at a more central level at their higher education institutions" (SHEA staff 1, September 2016), such as vice chancellors or deans; some international experience and experience in evaluations and working in groups are valuable. The guidelines urge thorough knowledge on the Swedish higher education system and quality assurance (SHEA 2016d, p. 13).

All aspects and perspectives should be assessed in relation to their specific criteria, and the instructions to the external panels specify that these "must be judged as satisfactory for the overall assessment to be positive" (SHEA 2016d, p. 13). Furthermore, the external panel should:

\footnotetext{
3 "Hawke" refers to the HEI that was under review. Other HEIs in our materials on institutional reviews were Eagle and Falcon.
} 
...focus on the results of the quality assurance procedure - that is - that it systematically and effectively ensures and improves the courses and programmes. In addition, an assessment will be conducted of how well the HEI's quality assurance procedure systematically identifies strengths and ensures they are maintained and developed, as well as how the areas for improvement are identified, followed up and addressed. In this context, the SHEA would like to emphasise that it is considered positive for the quality assurance procedure to be able to identify and manage deviations and areas for improvement. How relevant stakeholders are given the results of the quality assurance procedure is also to be assessed. (SHEA 2016d, p. 13)

A preliminary report from the external assessment panel should be sent to the HEIs under review for them to correct and comment on any factual errors. A final report is the basis for the SHEA decision, with the rating in the pilot on a two-point scale: approved or not approved (SHEA 2016d, p. 14). For HEIs that are not judged as approved, there are follow-ups within a year with reviews of the improvements deemed necessary by an external panel. The HEIs should then show what measures they have taken to come to correct these weaknesses. Experiences and good examples are also to be communicated in feedback conferences and dialogue with the HEIs under review independent of the judgements (SHEA 2016d, p. 14).

The SHEA staff who worked to develop the new EQA system are strong believers in evaluation and quality assurance. They expect that the institutional reviews will lead to "...the development of faculty competences - that they learn" (Eagle project leader SHEA, March 2017), or that "on a more overarching level, they [the HEIs, our clarification] will have to shape up (---) and hopefully this seeps down to the courses and programmes so they become better" (SHEA staff 5, March 2017). Other expectations concern the possibility that the institutional reviews enhance students' perspective and make the HEIs better prepare the students for working life, so that higher education is useful and the reviews ensure students' rights to good education. There are also some more cautious thoughts about what these reviews may do to the HEIs, albeit not many:

We must not forget that the choices we make when it comes to focus and our basis, become very normative for the higher education institutions' continued quality assurance work, and this is something that has to be handled responsibly. (-------)

Now when we do the institutional reviews, and focus is on talking about the ESG, that the higher education institutions should do their own follow-ups and evaluation. Of course, it is clear, that there will be a lot of focus on that now. (SHEA staff 1, September 2016)

\section{Comments on the Design Work of the Institutional Reviews}

The institutional reviews are aimed at assessing HEIs' internal quality assurance systems, and these have to live up to the ESG as is also expressed in the overall 2016 national EQA system. We have demonstrated the ambitious work the SHEA laid down in translating the ESG into Swedish and align the institutional reviews with them. Here, the influx of European quality assurance policy becomes or is transduced 
into actual design work and work with guidelines, templates, instructions, and training.

The SHEA also translated the institutional review guidelines into English. Translations from one language to another always pose some difficulties when it comes to expressing the meaning of the words. The citations from the two guidelines show that the term "control" (kontroll in Swedish) is translated to "examine" in the English language guidelines, and "contribute" to "development" in the Swedish version (bidra till kvalitetsutveckling in Swedish) is translated to "support improvements" in the English version. Our point is that policy and governing work always include translations of different kinds; these shifts in meaning may be more in tune with the ESG, as they are expressed in the English language. However, another type of translation is also visible in the design and implementation process of the institutional reviews: translating the ESG into criteria that are meaningful in a Swedish higher education institution context.

Notable in the institutional reviews are the rather strong political ambitions to get the HEIs to work more intensely on gender equality issues. A stress on HEIs to become more market oriented is visible in the requirement of representatives from that perspective in the external assessment panels and in this particular perspective in the guidelines. Similar changes in higher education have been reported from other countries in several studies (e.g. Massen and Stensaker 2011; Schuetze et al. 2012). Student influence is also stressed and goes hand in hand with an increased ambition to pay attention to students' rights, as a matter of individualised learning.

The behaviouristic understanding of education and learning is also evident in the institutional reviews, as the ESGs are so conspicuously used as a basis for judgement. We note that judgements and the process of assessment in these reviews are based on a theory of analytic assessment where separate judgements are made on each of the pre-set criteria and then aggregated. The final judgement is "then built up from a series of small-scale decisions. When the steps are followed systematically, the grade follows as a logic outcome" (Sadler 2009, p. 161). According to Sadler (2009), such assessments may be rather inadequate for making judgements based on more open-ended and compiled materials, such as those used in the self-evaluation report and interview answers.

Central to quality assurance would be what meaning "quality" is given in the design, in the guidelines, and in the actual processes. Our interpretation of the design and the guidelines of the institutional reviews is that quality in higher education is fundamentally constructed as equivalent to the existence of internal quality assurance systems at the HEIs, which should assure high quality. Whether or not such systems actually do so is not really possible to know, since "high quality" is not defined. On the other hand, our analysis shows that the design and guidelines signal and underline the goal-/objective- and outcomes-/results-oriented rationale of governing; a gender equality perspective; a labour market perspective; and a student influence perspective. This view of quality in higher education is only slightly compatible with what the vice chancellors expressed as quality in higher education in the chapter "Navigating Higher Education Institutions in Times of Quality Assurance - The Assumptive Worlds of Vice Chancellors". It is perhaps a conscious 
decision by the SHEA to leave the main part of handling the "What is quality?" question to the HEIs. It is also in line with what is commonly referred to as "academic freedom" (Polanyi 1951, in Hartl 2012, p. 310) or faculty power over the scientific content and assessment of quality, in research and higher education. However, the design of the institutional reviews requires the HEIs to set up internal quality assurance systems that match the criteria of all aspects and perspectives, circumscribing such power and power to decide how the HEIs' internal resources are best used to achieve good education and research practice.

\section{Discussion}

The 2016 EQA system's overall design and work, as well as the institutional reviews, are based on the ESG. This means that the European higher education and quality assurance policy now is fully incorporated in the Swedish higher education policy context. It still remains to be seen whether or not this system is considered by the ENQA to be independent enough in relation to the government. Throughout the design process, the SHEA worked diligently to align the national system and institutional reviews with the ESG. This work entailed interpretations and translations of different kinds and in Freeman's words: "to translate is to represent in a new form something previously or otherwise represented differently in another language or medium" (Freeman 2006, p. 1). We have shown that shifts in meaning exist in language translations but are used in order to make the ESG acceptable in the context of Swedish higher education context. This is in part how European policy travels and is made acceptable in different nations (e.g. Grek and Lawn 2012).

We interpret the design to show some particular Swedish values, including political stress on gender equality, the labour market, and student influence. Although not absent in global or European education policy, the refinement of those perspectives is related to increased political pressure and expectations of the entire Swedish education system to work more intensely in these directions.

The SHEA staff developed aspect areas, criteria, guidelines, etc. for the 2016 system. They worked with the ESG and how to help them function in the Swedish context. They worked with the incorporation of political demands on higher education (like gender equality and labour market perspectives) and constant dissemination of information. In this work, the SHEA also spent time and energy to consult several advisory and reference groups, as well as arranging discussions with stakeholders. These efforts lead to a comprehensive national EQA system further supported by the component institutional reviews. With the SHEA's clever requirements of the HEIs to take part in national EQA processes and to develop internal quality assurance systems, external and internal scrutiny merges and has the potential to reach far into educational practice. Hence, consequences of the institutional reviews will be that the HEIs are expected to live up to this comprehensiveness, which demands resources: not only must they develop and add to existing IQA systems; they must also organise internal work to respond to the 
requested activities of the other types of evaluations administered by the SHEA. For example, the programme evaluations judge their ability to meet national standards of goal attainment set by the external panels. Expectations of what knowledge, skills, and values to include in programmes and courses are thereby communicated to faculty and students, as well as how students' degree papers should be assessed, albeit indirectly. This is yet another signal and possible constitutive effect (Dahler Larsen 2012, 2014) that sustains the objective-/goal- and results-/outcomes-oriented rationale of governing higher education. It also represents a particular view of education, teaching, and learning that may influence teachers', students', and researchers' understanding of what it means to be a teacher or a student and the meaning of higher education and knowledge generation as processes. According to this rationale, education and research are conceived as entirely predictable, while learning and new scientific insights most often are open-ended and unpredictable. In Hopman's (2008) words, the design of the 2016 EQA system turns higher education into a "well-defined" problem, managed by external "expertise" using indicators and standards that direct what is expected from the HEIs.

In our description and analysis of the design of the 2016 EQA system, we have observed that the meaning of "quality" in higher education largely seems to rest on the existence of extensive internal quality assurance systems at the HEIs. Based on this fact, another possible constitutive effect may be that such a conception of quality becomes more widespread in the future (Dahler Larsen 2012, 2014).

\section{Finally}

The transformation of national EQA policy for higher education into a concrete design of a national system is part of the governing work at the state level, as we have shown in the description of the SHEA's work in setting up the 2016 EQA system. More everyday national EQA work also demands activities. Pilots were conducted to fine-tune the design of all four components and as an implementation strategy. What happened when the design was put into "action", so to speak? In the next chapter, we explore this by following the pilot of institutional reviews.

\section{References}

Bleiklie, I., \& Kogan, M. (2007). Organization and governance of universities. Higher Education Policy, 20, 477-493.

Clarke, J. (2015). Inspections. Governing at a distance. In S. Grek \& J. Lindgren (Eds.), Governing by inspection (pp. 11-26). London: Routledge.

Dahler-Larsen, P. (2012). Constitutive effects as a social accomplishment: A qualitative study of the political in testing. Education Inquiry, 3(2), 171-186. 
Dahler-Larsen, P. (2014). Constitutive effects of performance indicators: Getting beyond unintended consequences. Public Management Review, 16(7), 969-986.

Freeman, R. (2006) What is translation? Rethinking relationships between research, policy and practice. Unpublished paper. Edinburgh: University of Edinburgh.

Grek, S., \& Lawn, M. (2012). Europeanizing education. Governing a new policy space. Oxford: Symposium Books.

Hartl, P. (2012). Michael Polanyi on the freedom of science. Synthesis Philosophica, 54(2), 307-321.

Harvey, L. (2010). Evaluation for what? Teaching in Higher Education, 7(3), 245-263.

Harvey, L., \& Newton, J. (2004). Transforming quality evaluation. Quality in Higher Education, 10(2), 149-165.

Hopman, S. T. (2003). On the evaluation of curriculum reforms. Journal of Curriculum Studies, 35(4), 459-478.

Hopman, S. T. (2008). No child, no school, no state left behind: Schooling in the age of accountability. Journal of Curriculum Studies, 40(4), 417-456.

Marton, F., Hounsell, D. \& Entwistle, N. (Eds.) (2008). Hur vi lär (3rd ed.) [How we learn]. Stockholm: Norstedts akademiska förlag.

Massen, P., \& Stensaker, B. (2011). The knowledge triangle: European higher education policy logics and policy implications. Higher Education, 61, 757-769.

Ministry of Education. (2015). Promemoria. U2015/1626/UH. Kvalitetssäkring av högre utbildning [Quality assurance of higher education]. Retrieved 20 March 2015, http://www.regeringen.se/rapporter/2015/03/u20151626uh/

Murtonen, M., Gruber, H., \& Lehtinen, E. (2017). The return of behaviourist epistemology: A review of learning outcomes studies. Educational Research Review, 22, 114-128.

Owen, J. M. (2006). Program evaluation. Forms and approaches (3rd ed.). New York: Guilford Press.

Polanyi, M. (1951). Foundations of academic freedom. In M. Polanyi (Ed.), The logic of liberty. London: Routledge and Kegan Paul Ltd.

Sadler, R. (2009). Indetermancy in the use of preset criteria for assessment and grading. Assessment \& Evaluation in Higher Education, 34(2), 159-179.

Schuetze, H. G., Bruneau, W., \& Grosjean, G. (Eds.). (2012). University governance and reform. Policy, fads, and experience in international perspective. New York: Palgrave Macmillian.

SFS 1993:100. Högskoleförordning [The Higher Education Ordinance].

SHEA. (2016a). Nationellt system för kvalitetssäkring av högre utbildning. Redovisning av ett regeringsuppdrag. Rapport, 2016, 15. [National system for quality assurance of higher education. Presentation of a government assignment]. Stockholm: The Swedish Higher Education Authority.

SHEA. (2016b). National system for quality assurance of higher education. Presentation of a government assignment. Report, 2016, 15. Stockholm: The Swedish Higher Education Authority.

SHEA. (2016c). Vägledning för granskning av lärosätenas kvalitetssäkringsarbete. Pilotstudie [Guidelines for reviewing quality assurance procedures of higher education institutions. Pilot study]. Stockholm: The Swedish Higher Education Authority.

SHEA. (2016d). Guidelines for reviewing quality assurance procedures of higher education institutions. Pilot study. Stockholm: The Swedish Higher Education Authority.

SHEA. (2018a). Vägledning för utbildningsutvärdering på grundnivå och avancerad nivå [Guidelines for programme evaluation]. Stockholm: The Swedish Higher Education Authority.

SHEA. (2018b). Vägledning för granskning av lärosätenas kvalitetssäkringsarbete [Guidelines for reviewing quality assurance procedures of higher education institutions. In Swedish]. Stockholm: The Swedish Higher Education Authority. 
SHEA. (2019). Nyhetsbrev 14 februari. UKÄ siktar mot ENQA [Newsletter 14 February. The SHEA aims at ENQA]. Retrieved February 14, 2019, https://www.uka.se/om-oss/aktuellt/ intervjuer/2019-02-14-uka-siktar-mot-enqa.html

SHEA. (n.d.). SHEA presentation materials, October 2016. Stockholm: The Swedish Higher Education Authority.

Standards and Guidelines for Quality Assurance in the European Higher Education Area (ESG) (2015). Belgium, Brussels.

Open Access This chapter is licensed under the terms of the Creative Commons Attribution 4.0 International License (http://creativecommons.org/licenses/by/4.0/), which permits use, sharing, adaptation, distribution and reproduction in any medium or format, as long as you give appropriate credit to the original author(s) and the source, provide a link to the Creative Commons license and indicate if changes were made.

The images or other third party material in this chapter are included in the chapter's Creative Commons license, unless indicated otherwise in a credit line to the material. If material is not included in the chapter's Creative Commons license and your intended use is not permitted by statutory regulation or exceeds the permitted use, you will need to obtain permission directly from the copyright holder.

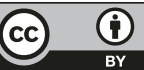

